\title{
Psychological Stress and Oxidative Damage in Lymphocytes of Aerobically Fit and Unfit Individuals ${ }^{1}$
}

\author{
Kelly Z. Knickelbein, ${ }^{3}$ Melanie Flint, Frank Jenkins, and \\ ANDREW BAUM ${ }^{2,4}$ \\ University of Pittsburgh Cancer Institute
}

\begin{abstract}
Habitual aerobic exercise has a beneficial effect on many systems of the body, and psychological stress has a negative influence on several of the same systems. One possible pathway is through those systems that account for the detrimental effects of stress; by buffering these harmful effects, exercise may reduce the consequences of stress. This study examined increased resistance of cells to stress-induced oxidative damage as a result of fitness. Forty healthy participants were assigned to either a stress group or a no-stress control group, and measures of stress and oxidative damage were collected. Variation in fitness level across participants was also measured. Oxidative damage increased as a function of stress, but this was not buffered by fitness level. These results should be interpreted with caution because of the small sample size and the limited variability of cardiorespiratory fitness levels in the sample.
\end{abstract}

Epidemiological evidence consistently suggests that regular physical activity and exercise reduce the risk of many diseases, including cardiovascular disease, Type 2 diabetes, and some forms of cancer (Booth, Chakravarthy, Gordon, \& Spangenburg, 2002). The specific protective mechanisms that contribute to this risk reduction have not been identified, but there are several possible pathways. Physiological changes known to occur as a result of habitual exercise have salutary effects on health, including lowered resting heart rate and blood pressure, more

${ }^{1}$ This research report is based on an MS thesis submitted to the University of Pittsburgh by the first author. It is based, in part, on support from the USARMC Breast Cancer Program (DAMD 17-010373). The authors would like to thank members of the thesis committee for their help with this project, including Anthony Caggiula, PhD, and John Jakicic, PhD. They would also like to thank Bret Goodpaster, PhD, and George Grove from the UPMC Exercise Physiology Laboratory, and Emily McLeod and William Riehl from the University of Pittsburgh Cancer Center for their support and assistance in conducting the tests and assays.

${ }^{2}$ Correspondence regarding this article should be addressed to Andrew Baum, PhD, Department of Psychology, University of Texas at Arlington, Arlington, TX 76019. E-mail: baum@uta.edu

${ }^{3}$ Present address: Graduate School of Public Health, University of Pittsburgh.

${ }^{4}$ Present address: University of Texas at Arlington and University of Texas Southwestern Medical Center.

Journal of Applied Biobehavioral Research, 2008, 13, 1, pp. 1-19.

(c) 2008 Copyright the Authors

Journal compilation (c) 2008 Wiley Periodicals, Inc. 


\section{KNICKELBEIN ET AL.}

efficient responses to changes in oxygen demand, reduced body fat, strengthened muscles, better immune function, higher maximal oxygen uptake, and improved oxidative outcomes (Irwin \& Friedman, 1999). People who participate in aerobic exercise over a prolonged period of time also exhibit beneficial adaptations of physiological systems that are activated during acute psychological stress, specifically the reactivity and recovery of heart rate and blood pressure in response to stress (Crews \& Landers, 1987; McCubbin, Cheung, Montgomery, Bulbulian, \& Wilson, 1992). This is consistent with the effects of acute and habitual exercise on hemodynamic responses and suggests that the "trained" body adapts to the challenges induced by acute exercise, rendering it more efficient at coping with subsequent stressors (Finkel \& Holbrook, 2000). These beneficial adaptations are the focus of this research, which examines the effects of fitness on acute stress and oxidative damage by evaluating stress-induced oxidative damage in the nuclear DNA of immune cells across different levels of fitness.

\section{Oxidative Balance}

Oxidative balance and load refer to the relative amounts of - or concentrations of-potentially damaging reactive oxygen species (ROS) and endogenous and exogenous antioxidants that neutralize them. ROS are highly reactive molecules with unpaired electrons. They are produced continuously in the body as a result of normal cellular processes. Oxidative balance is achieved when availability of oxidants and antioxidant compounds are comparable. When ROS exceeds the capacity of the body's antioxidant resources, unbuffered ROS appear that can cause damage to several cellular structures, including lipids, proteins, and DNA. Oxidative stress refers to this imbalance, which reflects breaching of the body's capacity to defend against ROS, resulting in production of oxidized bases, protein oxidation, and lipid peroxidation. These processes can cause cellular damage or degeneration and have been implicated in cell aging and the onset of chronic diseases such as cardiovascular disease, cancer, and degenerative diseases (Ames, Shigenaga, \& Hagen, 1993). Oxidative stress profiles are not entirely determined by ROS production, but also derive from limitations in oxidative defense systems. Defense against ROS damage consists of antioxidant enzymes, nonenzymatic antioxidants, and cellular repair mechanisms (Moller, Wallin, \& Knudsen, 1996). Major forms of defense include scavenging of reactive metabolites and converting them to less reactive molecules, enhancing the resistance of biological targets to ROS attacks, facilitating the repair of damage, and triggering the expression of genes that encode antioxidant proteins and cellular repair enzymes (Sen, 1995).

Several processes or behaviors can affect the balance of oxidants and antioxidants. It is generally accepted that most acute aerobic exercise increases the production of ROS (Alessio et al., 2000; Ashton et al., 1998; Jammes, Steinberg, Bregeon, \& Delliaux, 2004). Data are less clear when considering mechanisms in 
part because human studies have often relied on indirect measures of oxidative stress. These measures include by-products of oxidative damage to lipids, proteins, and DNA that require inferences about the causes of the damage. For example, several studies show that acute exercise causes elevated levels of plasma malondialdehyde, the reactive intermediate of lipid peroxidation, and carbonyls, reactive intermediates from protein oxidation (Alessio et al.; Jammes et al.; Tsai et al., 2001). These effects suggest changes in oxidative stress. Damage to nuclear DNA of leukocytes has also been shown 24 hours after completion of exhaustive exercise compared with resting levels, presumably as a function of increased oxidative stress (Niess, Hartmann, Grunert-Fuchs, Poch, \& Speit, 1996). Ashton and colleagues (1998) reported more direct measures of ROS in venous blood before and after exhaustive aerobic exercise, using electron spin resonance spectroscopy. All of these studies found that the ROS increased after exercise.

The primary source of ROS generation during exercise is believed to be increased respiration of mitochondria due to greater demand for energy in contracting muscles (Leeuwenburgh \& Heinecke, 2001). During aerobic activity, the reduction of molecular oxygen in mitochondria causes continuous generation of adenosine triphosphate for muscular contraction as a result of the electron transport chain. This process accounts for roughly $95 \%-98 \%$ of the total oxygen consumption of tissues, but the remainder may go through one electron reduction leading to the production of superoxide radicals $\left(\mathrm{O}_{2}{ }^{\circ}\right)$ and hydrogen peroxide $\left(\mathrm{H}_{2} \mathrm{O}_{2}\right)$, which are common forms of ROS in the body (Alessio et al., 2000; Jackson, 2000). The superoxide and hydrogen peroxide produced during contractile activity are then leaked from the muscle cells into the interstitial fluid, where they can form hydroxyl radicals (O'Neill, Stebbins, Bonigut, Halliwell \& Longhurst, 1996). Other pathways are also relevant because elevated oxygen consumption is not the only source of ROS production. Isometric exercise also induces increases in oxidative stress, although the increase is not as great as after an aerobic challenge (Alessio et al.). Other sources of ROS include phagocytic production of ROS as part of the inflammatory process, the autoxidation of catecholamines, and the generation by xanthine oxidase (Jackson).

Exercise training also increases antioxidant activity and repair of ROS damage (Fatouros et al., 2004; Miyazaki et al., 2001). Evidence shows an association between DNA damage in leukocytes, and exercise and reduction of this damage with physical conditioning (Hartmann, Plappert, Raddatz, GrunertFuchs, \& Speit, 1994; Niess et al., 1996; Radak et al., 2002; Tsai et al., 2001). Some of these studies considered very small sample sizes, some with fewer than a dozen participants, but they still found damage and training effects. Some reported a negative correlation between $\mathrm{VO}_{2}$ max and DNA damage despite methodological limitations (e.g., cross-sectional design, sample sizes, and potential confounding variables). 


\section{KNICKELBEIN ET AL.}

\section{Psychological Stress and DNA damage}

The first evidence of psychological stress-induced damage to nuclear DNA was shown in liver cells of rats exposed to a conditioned emotional stimulus (CES). Exposure to the CES produced more repair enzymes (e.g., 8-OH-dG) in nuclear DNA of the liver after the second, third, and fourth exposure with a return to baseline levels 1 hour after completion (Adachi, Kawamura, \& Takemoto, 1993). Human studies identified an association between student exams and increased DNA damage (Cohen, Marshall, Cheng, Agarwal, \& Wei, 2000; Forlenza, Latimer, \& Baum, 2000). Observed increases in repair were used to infer an increase in DNA damage occurring during psychological stress. More recently, research showed that medical students had more nuclear DNA damage in lymphocytes on the day of an examination than between examinations (Sivonova et al., 2004). Furthermore, in a recent study conducted by Flint, Baum, Chambers, and Jenkins (2007), the stress hormones, epinephrine (E), norepinephrine (NE), and cortisol, induced DNA damage in murine 3T3 cells exposed in vitro. Together, these studies provide some evidence that psychological stress affects DNA damage.

Exercise and stress both appear to increase oxidative damage and affect both sides of the oxidative balance. Although both tend to increase oxidative stress, fitness may increase the speed of recovery or adaptation to increased and unbuffered ROS caused by psychological stress. The present study was concerned with the extent to which exercise or fitness affected psychological stress impact on DNA damage. Damage to DNA in lymphocytes during an acute psychological stressor was compared among participants of varying fitness levels and with controls. Three time points were considered: before stressor exposure, immediately poststressor, and 20 minutes after the stressor. It was predicted that the group variable (stress/no stressor) would significantly affect DNA damage scores across time. The stress group was expected to show increased damage at Time 2 (immediately poststressor) compared with Time 1 (baseline), whereas damage in the control group was expected to remain unchanged. An interaction between group assignment and fitness level was also predicted, such that increases in damage would occur primarily in less fit participants and that recovery after the stressor would be more rapid in the fit participants.

\section{Methods}

\section{Participants}

A total of 40 men and women between the ages of 18 and 25 were recruited for this study. Participants were eligible for the study if they reported being sedentary 
or physically fit. A sedentary adult was defined as one who had not engaged in an exercise regimen exceeding 20 minutes per day, 3 days per week, over the previous 6 months (Jakicic, Marcus, Gallagher, Napolitano, \& Lang, 2003). Aerobically fit individuals were defined as those who reported engaging in 30 minutes or more of aerobic exercise at least 5 days per week over the previous 6 months. Cardiorespiratory fitness tests were used to objectively assess levels of fitness. Participants were excluded if they currently smoked or were taking medication that would influence cardiovascular or immune measures, including excessive alcohol ( $>10$ drinks/week) and illegal drugs. Participants with a medical condition, musculoskeletal injuries, or psychiatric diagnosis that might affect activity or immune system function were also excluded. This information was collected by self-report and included incidence cancer, asthma, arthritis, diabetes, heart disease, autoimmune disorders, major depression/anxiety, and hypertension. Participants who reported being overweight (body mass index $>27$ ) were also ineligible to participate. Participants were recruited through posted flyers and the undergraduate psychology subject pool Web site at the University of Pittsburgh. Participants were either paid or received credit toward their undergraduate psychology class.

\section{Measures}

Weight, body mass index, and percent body fat were measured using a body composition analyzer/scale (Tanita Corporation of America, Inc., Arlington Heights, IL). A submaximal graded exercise treadmill test was used to assess cardiorespiratory fitness as described by Jakicic et al. (2003). The treadmill was set to a constant speed of $80.4 \mathrm{~m} /$ minute, with the grade beginning at $0 \%$ and progressing by $2.5 \%$ at 3 -minute intervals until $85 \%$ of age-predicted maximal heart rate (computed as 220 minus age) was achieved. Maximum cardiorespiratory fitness $\left(\mathrm{VO}_{2} \max \right)$ was calculated by plotting results from the submaximal test and extrapolating out to the age-predicted maximal heart rate. The Pittsburgh Sleep Quality Index (PSQI) was used to examine sleep duration, sleep quality, and napping behavior over the past month (Buysse, Reynolds, Monk, Berman \& Kupfer, 1989). The PSQI has high internal validity and an overall reliability coefficient of .83 .

The Perceived Stress Scale (PSS) is a 14-item scale used to assess perceptions of stress by measuring the degree to which individuals appraise daily life events as unpredictable, uncontrollable, or overloading (Cohen, Kamarck, \& Mermelstein, 1983). The items ask about thoughts and feelings during the last month. The validity is adequate, and it has a reliability coefficient of .85 . The Interpersonal Support Evaluation List (ISEL) was used as a measure of perceived availability of supportive social resources (Cohen, Mermelstein, Kamarck, \& Hoberman, 1985). The ISEL consists of 40 statements that can provide an overall functional 
support measure or that can be separated into four separate functions of perceived support: appraisal, belonging, tangible support, and self-esteem. The ISEL has adequate validity and reliability and has demonstrated reasonable stability across time. The internal reliability of the total scale ranges from .88 to .90 . The internal reliability ranges for the subscales are .70-.82 for appraisal, .62-.73 for self-esteem, .73-.78 for belonging, and .73-.81 for tangible support.

General self-efficacy beliefs were assessed with the 10-item Generalized SelfEfficacy Scale or GSES (Schroder \& Schwarzer, 2005). The GSES has an internal reliability coefficient of .85 and sufficient validity. The Profile of Mood States short form (POMS-SF) is a 37-item measure used to assess current mood states. The original 65-item form comprises adjectives rated on a 5-point scale from not at all to extremely and can be divided into six factor-based subscales: TensionAnxiety, Depression-Dejection, Anger-Hostility, Fatigue-Inertia, Vigor-Activity, and Confusion-Bewilderment (McNair, Lorr, \& Droppleman, 1971). The POMS-SF retains the reliability of the six subscales in the range of .78-.91, and correlation with the original version has been found to be above 95 (Shacham, 1983).

\section{Biological Outcome Measures}

The majority of studies exploring exercise, stress, and/or oxidative damage have focused on plasma measures of ROS and endogenous antioxidants. However, effects at the cellular level have also received attention, particularly investigation into DNA damage and repair. ROS have the capacity to cause a range of DNA lesions, including modified nucleotide bases and strand breaks. If modified bases are not properly repaired prior to replication, the cell is in danger of potentially harmful mutations or apoptosis. Fortunately, defenses such as nucleotide excision repair exist to mend nucleotide base alterations before they damage the integrity of the genome or lead to cell death. A widely used biomarker of DNA damage is 8-hydroxydeoxyguanine (8-OH-dG), a DNA repair product found in the blood and urine (Griffiths et al., 2002). Levels of 8-OH-dG provide an estimate of the amount of base modification and subsequent repair that has taken place in the body but are ultimately indirect, inferring damage from extent of repair activity.

Single-cell gel electrophoresis, known as the comet assay, is another popular method used to determine the amount of oxidative DNA damage in cells, and it measures damage directly. The comet assay quantifies single strand breaks in DNA that occur as a result of oxidized bases. DNA from a variety of cells can be evaluated with this method, but lymphocytes are the most frequently examined cells in human studies. Because lymphocytes are thought to be sentinel cells and to provide early warning signs for negative health outcomes linked to oxidative damage (Faust, Kassie, Knasmuller, Kevekordes, \& Mersch-Sundermann, 2004), 
the choice of lymphocytes may also provide insight into how oxidative damage may affect the immune system.

\section{Procedure}

Eligibility screening occurred over the telephone prior to the first laboratory visit. During this screening, the study was explained and information was collected to determine eligibility. If eligible, the participants were scheduled to come into the laboratory on two separate occasions. Based on self-report of being sedentary or physically fit, an equal number of fit and unfit participants were randomly assigned to either the stressed experimental group or the non-stressed control group.

During the initial visit, the study was again explained, and informed consent obtained prior to participation. Information was collected on demographics, sleep quality, perceived stress, social support, self-efficacy, foods ingested in the previous 12 hours, and physical activity in the previous 12 hours. Following completion of the questionnaires, a butterfly needle was inserted into the antecubital vein of the nondominant arm and remained in place for 15 minutes before blood was taken. During this time, participants were instructed to relax and read magazines. Additionally, an automated blood pressure cuff was placed on the dominant arm to record blood pressure and heart rate at 3-5-minute intervals throughout the study as a manipulation check of the stressors. After the first blood draw, participants in the experimental condition engaged in two cognitive tasks, a speech task and the computer version of the Stroop Color and Word Test; both were chosen for their known ability to elicit a stress response. For the speech task, participants were instructed to defend themselves in front of a judge for being accused of shoplifting. They were given 2 minutes to prepare and 3 minutes to give the speech, which they were told was being recorded on a tape recorder. The speech task has been shown to effectively elicit cardiovascular and neuroendocrine responses (Stoney, Matthews, McDonald, \& Johnson, 1988). During the Stroop Color and Word Test, participants were asked to choose the print color of a color name from color names printed in different colors. This task also elicits cardiovascular and immune responses characteristic of stress (Manuck, Cohen, Rabin, Muldoon, \& Bachen, 1991). Immediately following the completion of the task, a second blood draw was taken. The POMS-SF was given before and after the stress tasks to assess current mood and as an additional manipulation check of the stressors. Participants were then instructed to relax and read magazines before the third blood draw, taken 20 minutes later (Figure 1). After the third blood draw, the butterfly needle and blood pressure cuff were removed. Participants in the control condition underwent the same procedures as the experimental group, except instead of completing the cognitive tasks, they were instructed to read magazines during the stressor period. All 


\begin{tabular}{|c|c|c|}
\hline$\uparrow$ & Cognitive Tasks & 20 minute Recovery \\
\hline Baseline & Blood draw 2 & Blood draw 3 \\
\hline \multicolumn{3}{|c|}{ Blood draw 1} \\
\hline Time 1 & Time 2 & Time 3 \\
\hline
\end{tabular}

Figure 1. Timeline of blood draws.

participants also received instructions on how to access the Web-based diet history questionnaire. Participants were debriefed at the conclusion of the session.

The second lab visit was scheduled for the same week or the week following the first visit. During the second lab visit, the study was again explained to the participant, and body composition was measured. Participants then performed the submaximal $\mathrm{VO}_{2}$ test to get an estimate of their cardiorespiratory fitness.

\section{Data Collection}

A total of three $15 \mathrm{~mL}$ blood samples were collected from each participant. Samples were placed immediately in EDTA tubes to avoid coagulation. Mononuclear cells were isolated by Ficoll Hypaque centrifugation, as described by Kanof, Smith, and Zola (1996). Cell viability was assessed by trypan blue dye exclusion, and cells were counted under a microscope with a hemocytometer.

The comet assay was used to assess the amount of DNA damage in the lymphocytes. This technique is a widely accepted and reliable method, as proved in many testing circumstances (Collins et al., 1997; Hartmann et al., 2003). As described by Collins (2004), cells were suspended in agarose gel, then placed on slides and immersed in a lysis solution for 1 hour. Slides were then placed in an electrophoresis chamber to allow for the separation of damaged DNA strands. Slides were washed and stained with ethidium bromide before examination under an ultraviolet microscope. Visual scoring on each slide was based on the characterization of 100 randomly selected nucleoids, which are put into 1 of 5 classes $(0,1,2,3,4)$ representing the increasing extent of DNA damage seen in the tail of the "comet." Each comet was assigned a value according to its class, and the overall score for 100 comets ranges from 0 -indicating that $100 \%$ of the comets were scored as being in Class 0 with no damage - up to 400, in which $100 \%$ of the comets fell into Class 4 with maximum damage. The same two experienced researchers using a specific pattern when moving along the slide carried out the observation and analysis. The observers had no knowledge of the identity of the slide during evaluation. Intraclass correlation (ICC) analysis was used to determine interrater reliability for the DNA damage scores from the two blind 
raters. An examination of $50 \%$ of the scores revealed that interrater reliability was adequately high, $r(54)=.96, p<.01$.

\section{Data Analysis}

Descriptive statistics and frequency distributions were obtained for each variable of interest. Associations between baseline demographic data and biological outcome variables were examined with Pearson product-moment correlations to determine the variables to be used as covariates in further analyses. Independent $t$ tests were also conducted to examine if significant differences existed between the stress and control groups for demographic and psychosocial measures.

To verify that the stress manipulation was successful, $2 \times 3$ repeated measures analyses of variance (ANOVAs) were conducted. Separate analyses were run using heart rate (HR), systolic blood pressure (SBP), diastolic blood pressure (DBP), and POMS anxiety scores as dependent variables, with group assignment (stress/nonstressed) as the between-subjects variable, and time (Time 1, Time 2, Time 3) as the within-subjects variable.

To test the response of DNA damage to the stress tasks, a $2 \times 2$ repeated measures analysis of covariance (ANCOVA) was performed using raw DNA damage scores as the dependent variable, group assignment as the betweensubjects variable, and time (Time 1, Time 2) as the within-subjects variable. DNA damage at Time 3 (recovery period) was not included in the analyses because a large number of participants in the sample $(n=14)$ did not give a sufficient amount of blood at this time point. Pearson product-moment correlations revealed that age was significantly associated with DNA damage scores, $r(38)=-.33, p<.05$, and it was subsequently used as a covariate in the analyses.

A hierarchical multiple regression analysis was performed to test whether the strength of the effect of the stress condition on DNA damage depended on fitness level. Fitness was assessed by the scores on the $\mathrm{VO}_{2}$ submaximal test and was treated as a continuous variable in the regression analysis. To carry out the regression analysis, it was necessary to calculate difference scores for DNA damage by subtracting the amount of damage at Time 2 (after the stress task) from the damage found at Time 1 (baseline). The difference score served as the dependent variable. Age was entered in the first step as a covariate, followed by fitness level and group assignment in the next steps. The interaction term, Group $\times$ Fitness, was entered in the final step. Relationships were determined by examining the variance in DNA damage explained by the two-way interaction between stress condition and fitness level, over and above the main effects of each variable separately. 
Results

The sample for this study consisted of 40 participants, with 20 in the stress condition and 20 in the nonstressed control condition. A demographic profile of this sample is provided in Table 1. Independent $t$ tests (see Table 2) showed no significant statistical differences $(p>.05)$ among demographic or psychosocial variables between individuals in the stress group and those in the control group. All participants reported being nonsmokers, drinking fewer than 10 alcoholic drinks per week, and generally in good health. Frequency distribution for $\mathrm{VO}_{2}$ max scores in the overall sample is illustrated in Figure 2. The sample was normally distributed but somewhat more fit than had been anticipated.

\section{Stress Manipulation}

Results indicated that the stress manipulation was successful. The $2 \times 3$ repeated measures ANOVA yielded a significant interaction of group and time for HR, $F(1,38)=1.44, p<.01$, partial eta ${ }^{2}=.28$; SBP, $F(1,38)=19.45, p<.01$, partial eta ${ }^{2}=.34$; and DBP, $F(1,38)=28.72, p<.01$, partial eta ${ }^{2}=.43$ (see Figure 3). HR, SBP, and DBP were comparable at baseline for both stress and no-stress participants, but they diverged at Time 2 (after tasks). In the stress group, participants' HR, SBP, and DBP significantly increased at Time 2 and returned to near baseline levels at Time 3. Participants in the no-stress group showed little or no change over time. The POMS anxiety scores did not show an interaction effect, $F(1,38)=.159, p<.05$, partial eta ${ }^{2}=.004$.

Table 1

Demographic Variable Means and Standard Deviations

\begin{tabular}{lccc}
\hline & $\begin{array}{c}\text { Entire sample } \\
n=40\end{array}$ & $\begin{array}{c}\text { Stress condition } \\
n=20\end{array}$ & $\begin{array}{c}\text { Control condition } \\
n=20\end{array}$ \\
\hline Gender (\% male) & $22 / 40(55 \%)$ & $12 / 20(60 \%)$ & $10 / 20(50 \%)$ \\
Age $(S D)$ & $21.6(2.5)$ & $22.1(2.5)$ & $21.2(2.4)$ \\
Ethnicity (\% & $31 / 40(77.5 \%)$ & $15 / 20(75 \%)$ & $16 / 20(80 \%)$ \\
$\quad$ Caucasian) & & & \\
BMI $(S D)$ & $22.4(2.8)$ & $22.4(2.6)$ & $22.6(3.1)$ \\
Body Fat \% (SD) & $18.7(6.8)$ & $17.8(6.9)$ & $19.6(6.7)$ \\
$\mathrm{VO}_{2}(\mathrm{~mL} / \mathrm{kg} /$ minute) & $45.9(11.9)$ & $48.9(13.4)$ & $42.9(9.7)$ \\
$(S D)$ & & & \\
\hline
\end{tabular}

$\mathrm{BMI}=$ body mass index; $\mathrm{SD}=$ standard deviation. 
Table 2

Mean Levels of Demographic and Psychosocial Variables in the Stress and No-Stress Groups

\begin{tabular}{|c|c|c|c|c|c|c|}
\hline & $\begin{array}{c}\text { Group } \\
\text { assignment }\end{array}$ & $n$ & Mean & $S D$ & $t$ & $\begin{array}{c}\text { Sig. } \\
\text { (2-tailed) }\end{array}$ \\
\hline \multirow[t]{2}{*}{$\mathrm{VO}_{2}(\mathrm{~mL} / \mathrm{kg} / \mathrm{minute})$} & Stress & 20 & 42.90 & 9.69 & -1.63 & .11 \\
\hline & No stress & 20 & 48.90 & 13.37 & & \\
\hline \multirow[t]{2}{*}{ Age } & Stress & 20 & 21.15 & 2.43 & -1.23 & .23 \\
\hline & No stress & 20 & 22.10 & 2.47 & & \\
\hline \multirow[t]{2}{*}{ Gender } & Stress & 20 & 1.50 & .51 & -.62 & .54 \\
\hline & No stress & 20 & 1.60 & .50 & & \\
\hline \multirow[t]{2}{*}{ PSS Total } & Stress & 20 & 14.90 & 4.88 & -.40 & .69 \\
\hline & No stress & 20 & 15.55 & 5.31 & & \\
\hline \multirow[t]{2}{*}{ ISEL total } & Stress & 20 & 18.05 & 6.61 & -.26 & .80 \\
\hline & No stress & 20 & 19.05 & 15.92 & & \\
\hline \multirow[t]{2}{*}{ GSES total } & Stress & 20 & 6.80 & 2.98 & .99 & .33 \\
\hline & No stress & 20 & 5.80 & 3.38 & & \\
\hline \multirow[t]{2}{*}{ PSQI total } & Stress & 20 & 8.45 & 5.20 & -.63 & .53 \\
\hline & No stress & 20 & 9.50 & 5.35 & & \\
\hline \multirow[t]{2}{*}{ BMI } & Stress & 20 & 22.57 & 3.09 & .22 & .83 \\
\hline & No stress & 20 & 22.37 & 2.56 & & \\
\hline \multirow[t]{2}{*}{ Body fat $\%$} & Stress & 20 & 19.64 & 6.74 & .84 & .41 \\
\hline & No stress & 20 & 17.84 & 6.92 & & \\
\hline
\end{tabular}

BMI = body mass index; GSES = Generalized Self-Efficacy Scale; ISEL = Interpersonal Support Evaluation List; PSQI = Pittsburgh Sleep Quality Index; PSS = Perceived Stress Scale; $\mathrm{SD}=$ standard deviation.

\section{Effect of Group Assignment on DNA Damage}

It was expected that the stress group would have increased DNA damage after the stress tasks compared with baseline and that the control group would not exhibit this increase in damage. Results from a $2 \times 2$ (Group $\times$ Time) repeated 


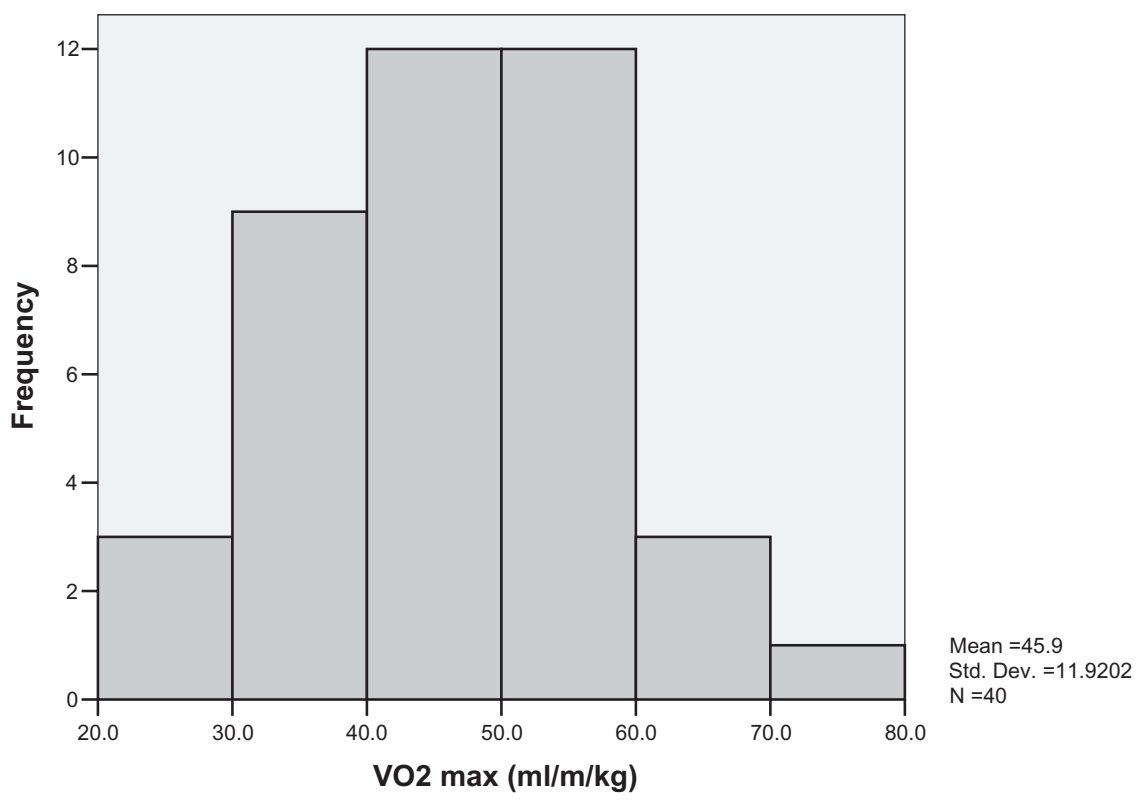

Figure 2. Frequency distribution for $\mathrm{VO}_{2} \max$ scores in the overall sample.

measures ANCOVA supported this hypothesis. There was a significant interaction between group assignment and time, $F(1,38)=4.1, p<.05$, partial eta ${ }^{2}=.10$, indicating that DNA damage increased from Time 1 to Time 2 only in the stress group (see Figure 4).

\section{Impact of Fitness Level}

It was hypothesized that the interaction between cardiorespiratory fitness and group assignment would significantly predict the change in DNA damage between Time 1 and Time 2 over and above the effects of each variable individually. As shown in Table 3, age and group assignment significantly predicted variance in DNA damage difference scores. Age accounted for $11 \%$ of the variance, and group assignment accounted for $9 \%$ of the variance. No main effect for fitness was detected, and the interaction between fitness and group assignment did not influence damage over and above the independent main effects of age and group assignment.

\section{Discussion}

Psychological stress and exercise affect overall health and cellular functioning in different ways. It is well known that habitual aerobic exercise has a 


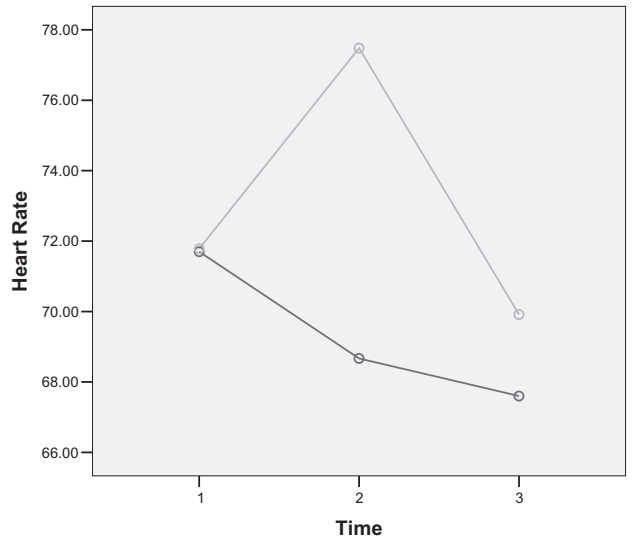

Group Assignment

$$
\text { — No stress }
$$

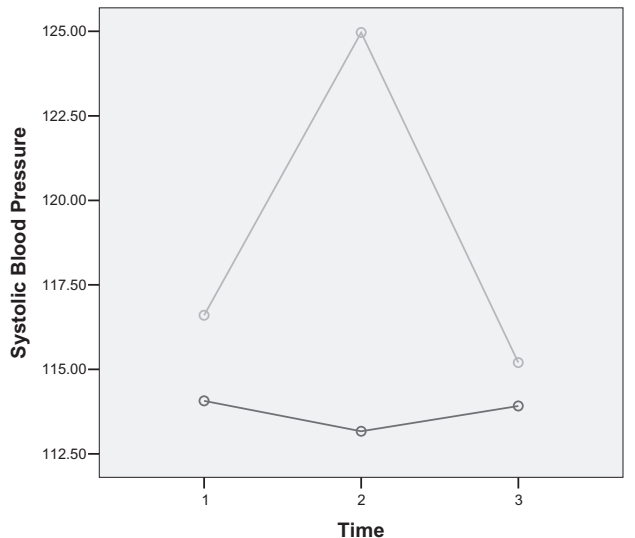

Group Assignment — No stress - stress

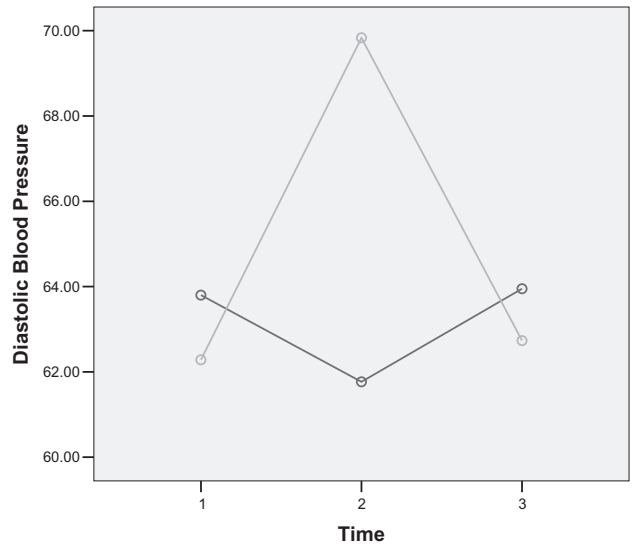

Group Assignment - No stress

- stress

Figure 3. Effect of stress manipulation on hemodynamic measures in the stress and no-stress groups across time. 


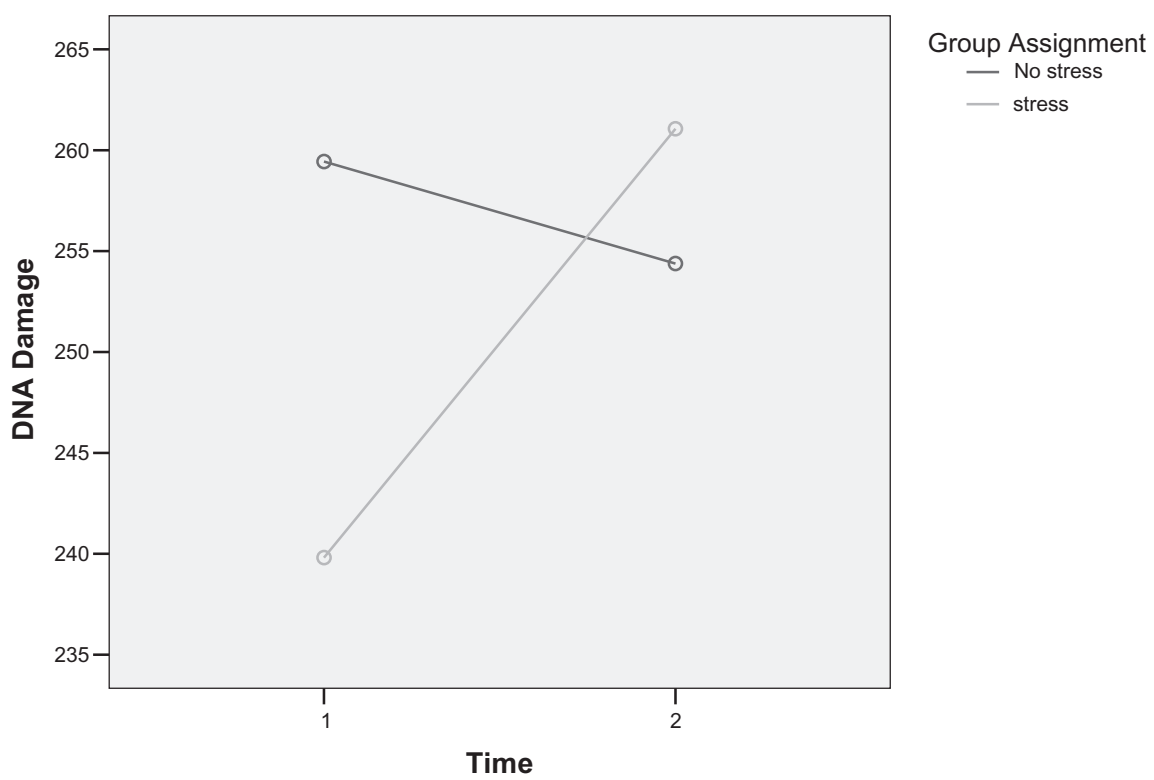

Figure 4. DNA damage across time between the stress and no-stress groups.

Table 3

Regression Analysis for the Interaction of Group Assignment and Fitness Level on DNA Damage Difference Scores

\begin{tabular}{lrrrc}
\hline Predictor & \multicolumn{1}{c}{$\mathrm{B}$} & \multicolumn{1}{c}{$\mathrm{SE}$} & \multicolumn{1}{c}{$t$} & $p$ \\
\hline Age & -6.27 & 2.72 & -2.31 & $.03^{*}$ \\
Group Assignment & 30.73 & 13.29 & 2.31 & $.03^{*}$ \\
$\mathrm{VO}_{2}(\mathrm{~mL} / \mathrm{kg} /$ minute $)$ & -1.03 & .97 & -1.06 & .30 \\
Group* $\mathrm{VO}_{2} \max$ & .37 & 1.19 & .31 & .16 \\
\hline
\end{tabular}

$\mathrm{B}=$ beta $; \mathrm{SE}=$ standard error.

${ }^{*} p<.05$ (2-tailed).

beneficial effect by lowering resting heart rate and blood pressure, reducing body fat, strengthening muscles, enhancing immune function, increasing maximal oxygen uptake, and improving oxidative outcomes (Irwin \& Friedman, 1999). Psychological stress and exercise appear to influence immune and neuroendocrine functioning and increase oxidative burden, and it is possible 
that this is due to increases in stress hormones and ROS and leads to increases in DNA damage. The primary aims of this study were to expand upon previous evidence that psychological stress leads to increased DNA damage and to determine if the benefits of exercise extend to protecting cells from this damage.

Results of this study were consistent with previous studies and provide novel evidence for the impact of psychological stress on DNA damage. It has been shown that exam stress is linked to increased DNA damage (Sivonova et al., 2004), but this is the first study to find a significant effect of acute laboratory stress on a direct measure of DNA damage in humans. This could have implications for health, particularly if stress becomes chronic and DNA damage is not repaired by the body's natural repair mechanisms. Although DNA damage scores at the recovery point (Time 3 ) were not included in the statistical analyses, of the 13 participants in the stress group who did provide Time 3 samples, trends suggest that DNA damage decreases toward baseline levels fairly quickly. This implies that damage can be repaired quickly and would probably not have a detrimental effect on cellular functioning if repair mechanisms are operating correctly or if stress is brief or readily resolved.

The mechanisms by which DNA damage occurs during acute psychological stress still remain unknown, although recent studies have begun to examine possible explanations. Flint et al. (2007) suggested that hormones released in the body during stress, particularly cortisol, NE, and E, can cause DNA damage within 10 minutes. The authors proposed that the hormones induce damage by binding to cell surface receptors and triggering a series of intracellular signals. It is important to recognize that circulating cells in the human body may respond very differently, and more research is needed to bridge the gap between the response of murine cells and the response of active cells in humans. Future studies are needed to measure plasma ROS in response to stress in order to better understand the influence of acute psychological stress on cellular processes.

Contrary to our hypothesis, cardiorespiratory fitness levels did not buffer the impact of acute psychological stress on DNA damage. It was hypothesized that the systems involved would exhibit enhanced plasticity as a function of beneficial adaptations associated with fitness as a result of habitual aerobic exercise, and that fit individuals might have stronger antioxidant and DNA repair responses and be better prepared to resist DNA damage in response to psychological stress. Several limitations of this study could have been responsible; the sample size, though robust for studies of this genre, may have been too small to detect these effects. In relation to this, the impact of acute laboratory stress on oxidative damage may not have been strong enough to allow observation of fitness-related modulation of them. Alternatively, the sample recruited for this study did not exhibit as wide a range of cardiovascular fitness levels as had been anticipated. As can be seen in Figure 1, fitness scores were evenly distributed, but the range was 
limited. With a mean $\mathrm{VO}_{2} \max$ of $45.9 \mathrm{~mL} / \mathrm{kg} /$ minute, and most falling between 40 and $60 \mathrm{~mL} / \mathrm{kg} / \mathrm{minute}$, this sample would be considered "above average" in fitness compared with the average population of 18-25-year-olds. According to the American College of Sports Medicine, men aged 18-25 need a score of at least $44.5 \mathrm{~mL} / \mathrm{kg} / \mathrm{minute}$, and women need a score of at least $35.2 \mathrm{~mL} / \mathrm{kg} / \mathrm{minute}$ to be in the top 50th percentile. This makes it difficult to discuss these results with any degree of certainty because the analysis may have been considerably different had more unfit individuals been included in this study.

Adaptations in oxidative stress profiles that occur as a result of regular exercise are assumed to be in response to cellular alterations, but cellular and molecular mechanisms that are responsible for these changes have not been identified. It has been suggested that ROS may trigger the activation of specific cellular stress-signaling pathways that help the cells respond to stress (Finkel \& Holbrook, 2000). The common effect of activating these pathways is to modulate transcription factor activity and alter the expression patterns of genes that may play a role in cell protection. It is possible that the mere presence of elevated ROS levels serves as a signal to turn on the multitude of defenses the body has against oxidative damage (Powers \& Sen, 2000). A more efficient and faster acting cellular defense system for combating ROS would presumably be beneficial during times of elevated ROS production, whether it be during an acute bout of exercise, during exposure to an oxidative stress-inducing agent, or during times of psychological stress.

\section{References}

Adachi, S., Kawamura, K., \& Takemoto, K. (1993). Oxidative damage of nuclear DNA in liver of rats exposed to psychological stress. Cancer Research, 53, 4153-4155.

Alessio, H. M., Hagerman, A. E., Fulkerson, B. K., Ambrose, J., Rice, R. E., \& Wiley, R. L. (2000). Generation of reactive oxygen species after exhaustive aerobic and isometric exercise. Medicine and Science in Sports and Exercise, $32,1576-1581$.

Ames, B. N., Shigenaga, M. K., \& Hagen, T. M. (1993). Oxidants, antioxidants, and the degenerative diseases of aging. Proceedings of the National Academy of Sciences USA, 90, 7915-7922.

Ashton, T., Rowlands, C. C., Jones, E., Young, I. S., Jackson, S. K., Davies, B., et al. (1998). Electron spin resonance spectroscopic detection of oxygencentred radicals in human serum following exhaustive exercise. European Journal of Applied Physiology and Occupational Physiology, 77, 498-502.

Booth, F. W., Chakravarthy, M. V., Gordon, S. E., \& Spangenburg, E. E. (2002). Waging war on physical inactivity: using modern molecular ammunition against an ancient enemy. Journal of Applied Physiology, 93, 3-30. 
Buysse, D. J., Reynolds, C. F., III, Monk, T. H., Berman, S. R., \& Kupfer, D. J. (1989). The Pittsburgh Sleep Quality Index: A new instrument for psychiatric practice and research. Psychiatry Research, 28, 193-213.

Cohen, L., Marshall, G. D., Jr. Cheng, L., Agarwal, S. K., \& Wei, Q. (2000). DNA repair capacity in healthy medical students during and after exam stress. Journal of Behavioral Medicine, 23, 531-544.

Cohen, S., Kamarck, T., \& Mermelstein, R. (1983). A global measure of perceived stress. Journal of Health and Social Behavior, 24, 385-396.

Cohen, S., Mermelstein, R., Kamarck, T., \& Hoberman, H. M. (1985). Measuring the functional components of social support. In I. G. Sarason, \& B. R. Sarason (Eds.), Social support: Theory, research and applications (pp. 73-94). The Hague, The Netherlands: Martinus Nijhoff.

Collins, A. R. (2004). The comet assay for DNA damage and repair: Principles, applications, and limitations. Molecular Biotechnology, 26, 249-261.

Collins, A., Dusinska, M., Franklin, M., Somorovska, M., Petrovska, H., Duthie, S., et al. (1997). Comet assay in human biomonitoring studies: Reliability, validation, and applications. Environmental and Molecular Mutagenesis, 30, 139-146.

Crews, D. J., \& Landers, D. M. (1987). A meta-analytic review of aerobic fitness and reactivity to psychosocial stressors. Medicine and Science in Sports and Exercise, 19(Suppl. 5), S114-S120.

Fatouros, I. G., Jamurtas, A. Z., Villiotou, V., Pouliopoulou, S., Fotinakis, P., Taxildaris, K., et al. (2004). Oxidative stress responses in older men during endurance training and detraining. Medicine and Science in Sports and Exercise, 36, 2065-2072.

Faust, F., Kassie, F., Knasmuller, S., Kevekordes, S., \& Mersch-Sundermann, V. (2004). Use of primary blood cells for the assessment of exposure to occupational genotoxicants in human biomonitoring studies. Toxicology, 198, 341350 .

Finkel, T., \& Holbrook, N. J. (2000). Oxidants, oxidative stress and the biology of ageing. Nature, 408(6809), 239-247.

Flint, M. S., Baum, A., Chambers, W. H., \& Jenkins, F. J. (2007). Induction of DNA damage, alteration of DNA repair and transcriptional activation by stress hormones. Psychoneuroendocrinology, 32, 470-479.

Forlenza, M. J., Latimer, J. J., \& Baum, A. (2000). The effects of stress on DNA repair capacity. Psychology and Health, 15, 881-891.

Griffiths, H. R., Moller, L., Bartosz, G., Bast, A., Bertoni-Freddari, C., Collins, A., et al. (2002). Biomarkers. Molecular Aspects of Medicine, 23(1-3), 101208.

Hartmann, A., Agurell, E., Beevers, C., Brendler-Schwaab, S., Burlinson, B., Clay, P., et al. (2003). Recommendations for conducting the in vivo alkaline Comet assay: 4th International Comet Assay Workshop. Mutagenesis 45-51. 
Hartmann, A., Plappert, U., Raddatz, K., Grunert-Fuchs, M., \& Speit, G. (1994). Does physical activity induce DNA damage? Mutagenesis, 9, 269 272.

Irwin, M., \& Friedman, E. (1999). Acute exercise and the cellular immune system. In M. Schedlowski \& U. Tewes (Eds.), Psychoneuroimmunology: An interdisciplinary introduction (pp. 342-358). New York: Kluwer Academic/Plenum.

Jackson, M. J. (2000). Exercise and oxygen radical production by muscle. In C. K. Sen, L. Packer, \& O. Hanninen (Eds.), Handbook of oxidants and antioxidants in exercise (pp. 57-68). Amsterdam: Elsevier Science.

Jakicic, J. M., Marcus, B. H., Gallagher, K. I., Napolitano, M., \& Lang, W. (2003). Effect of exercise duration and intensity on weight loss in overweight, sedentary women: A randomized trial. The Journal of the American Medical Association, 290, 1323-1330.

Jammes, Y., Steinberg, J. G., Bregeon, F. \& Delliaux, S. (2004). The oxidative stress in response to routine incremental cycling exercise in healthy sedentary subjects. Respiratory Physiology and Neurobiology, 144, 81-90.

Kanof, M. E., Smith, P. D., \& Zola, H. (1996). Preparation of human mononuclear cell populations and subpopulations. In C. J. E. A. M. Kruisbeek, D. H. Margulies, E. M. Shevach, \& W. Strober (Eds.), Current protocols in immunology (Vol. 2, p. 7.1.1). New York: Wiley.

Leeuwenburgh, C., \& Heinecke, J. W. (2001). Oxidative stress and antioxidants in exercise. Current Medicinal Chemistry, 8, 829-838.

Manuck, S. B., Cohen, S., Rabin, B. S., Muldoon, M. F., \& Bachen, E.A. (1991). Individual differences in cellular immune response to stress. Psychological Science, 2, 111-115.

McCubbin, J. A., Cheung, R., Montgomery, T. B., Bulbulian, R., \& Wilson, J. F. (1992). Aerobic fitness and opioidergic inhibition of cardiovascular stress reactivity. Psychophysiology, 29, 687-697.

McNair, D. M., Lorr, M., \& Droppleman, L. F. (1971). Manual for the Profile of Mood States. San Diego, CA: Educational and Industrial Testing Service.

Miyazaki, H., Oh-ishi, S., Ookawara, T., Kizaki, T., Toshinai, K., Ha, S., et al. (2001). Strenuous endurance training in humans reduces oxidative stress following exhausting exercise. European Journal of Applied Physiology, 84, 1-6.

Moller, P., Wallin, H., \& Knudsen, L. E. (1996). Oxidative stress associated with exercise, psychological stress and life-style factors. Chemico-Biological Interactions, 102, 17-36.

Niess, A. M., Hartmann, A., Grunert-Fuchs, M., Poch, B., \& Speit, G. (1996). DNA damage after exhaustive treadmill running in trained and untrained men. International Journal of Sports Medicine, 17, 397-403.

O’Neill, C. A., Stebbins, C. L., Bonigut, S., Halliwell, B., \& Longhurst, J. C. (1996). Production of hydroxyl radicals in contracting skeletal muscle of cats. Journal of Applied Physiology, 81, 1197-1206. 
Powers, S. K., \& Sen, C. K. (2000). Physiological antioxidants and exercise training. In C. K. Sen, L. Packer, \& O. Hanninen (Eds.), Handbook of oxidants and antioxidants in exercise (pp. 221-242). Amsterdam: Elsevier Science.

Radak, Z., Naito, H., Kaneko, T., Tahara, S., Nakamoto, H., Takahashi, R., et al (2002). Exercise training decreases DNA damage and increases DNA repair and resistance against oxidative stress of proteins in aged rat skeletal muscle. Pflugers Archiv: European Journal of Physiology, 445, 273-278.

Schroder, K. E., \& Schwarzer, R. (2005). Habitual self-control and the management of health behavior among heart patients. Social Science and Medicine, $60,859-875$.

Sen, C. K. (1995). Oxidants and antioxidants in exercise. Journal of Applied Physiology, 79, 675-686.

Shacham, S. (1983). A shortened version of the Profile of Mood States. Journal of Personality Assessment, 47, 305-306.

Sivonova, M., Zitnanova, I., Hlincikova, L., Skodacek, I., Trebaticka, J., \& Durackova, Z. (2004). Oxidative stress in university students during examinations. Stress, 7, 183-188.

Stoney, C. M., Matthews, K. A., McDonald, R. H., \& Johnson, C. A. (1988). Sex differences in lipid, lipoprotein, cardiovascular, and neuroendocrine responses to acute stress. Psychophysiology, 25, 645-656.

Tsai, K., Hsu, T. G., Hsu, K. M., Cheng, H., Liu, T. Y., Hsu, C. F., et al. (2001). Oxidative DNA damage in human peripheral leukocytes induced by massive aerobic exercise. Free Radical Biology and Medicine, 31, 1465-1472. 